\title{
The Combination of Language and Image - Scorsese's edition The Age of Innocence
}

\author{
Weina Ouyang \\ Foreign Language Education College of Beihua University, Jilin, Jilin, 132000 \\ 694839505@qq.com
}

Keywords: Setting of scene; Life of art; Pygmalion; Symbol; Narration

\begin{abstract}
Vivid description by combing painting and writing is characterized in Wharton's Age of Innocence, in which the extravagant and hypocritical upper class of society in Old New York is reproduced. When the art of language is brilliant enough, the real life will come to the life, just like the example in Scorsese's edition of the novel. Though a distance from the culture and historical the freedom and philosophy that heroes pursue for all of their lives are easily founded. Through the refinement of its filming, the images and pictures are clearer for the Wharton's readers.
\end{abstract}

\section{Introduction}

Edith Wharton had no much interest in what Hollywood now calls "the product" and didn't not see either of the two movie versions of The age of Innocence that were released during her lifetime. She thought that cinema that stressed its entertainment rather than its artistic values. Had Wharton been able to see Martin Scorsese's 1993 adaptation of her novel, however, she might have experienced a conversion. Seen in this light as the convergence of literary and painterly concerns, film as a medium might very well have appealed to Edith Wharton, for the combination of language and image is figured in Wharton's fiction: a preoccupation with the visual is central to her writing.

\section{Setting of Scene: Vivid Description of Wharton's Memory}

Wharton's the Age of Innocence is such an example; from the vivid description we can visualize the scene actually. The background of the novel is the upper-middle-class New York society, which is Wharton's remarkably fresh and abundant memory. The physical settings she could still so vividly recall, here is New York itself, with it interminable brownstones and its rival opera houses, its Gramercy Park Washington Square Central, its new Metropolitan Museum. [1] All details that Wharton can remember clearly after many years lie in contempt as well as nostalgia for the generation of Wharton. Old New York, Wharton's term to describe this wealthy and elite class at the top of the developing city's social hierarchy was a society utterly intent on maintaining its own rigid stability, manners, fashions, behaviors, and even conversations.

Scorsese' fidelity to the novel made the recurrence of the extravagant scene possible. Thanks to the picturesque description in Wharton's writing, we can see the grand and beautiful opening in the beginning of the film. At the same time it is such a place where he hero Archer is confined and couldn't escape. From Scorsese' edition, we can feel the repressive mood of Archer under the solemn and hypocritical atmosphere in his camera circling the ground. From the point on, the die is cast which is the destined tragedy. [2] Those who breached the social code were punished, with exquisite politeness, by the other members. As Wharton's narrator puts it, "in reality they all lived in a kind of hieroglyphic world, where the real thing was never said or done or even thought, but only represented by a set of arbitrary signs"[3]. So "the New York of Newland Archer's day was a small and slippery pyramid, in which, as yet, hardly a fissure had been made or a foothold gained." [3] Clearly, the theme of the novel is showed here if you observe the surrounding that both Wharton and Scorsese created. The Age of Innocence, then, stands as both a personal recollection of the culture of Wharton's youth with complicated mentality and an historical study of an old-fashioned world on the brink of profound and permanent change. 


\section{Falling Love with Ellen: Life of Art}

For Archer, a man of sensibility, who gradually escapes from the strict decorum and from what he takes to be the stifling lack of imagination of New York society into a world of literature and painting after being bored with them, the appearance of Ellen is an incarnation of the life of art. She represents the decadent European world of culture. The conflict between social codes and the yearning to break free play itself out both in the arena of the erotic and in the desire to lead a more unconventional life, a life of reading artistic. Since, for Newland, art is the suppressed realm both of the imagination and of the erotic. It is not surprising that he chooses the art museum as the location of their tryst. This is perhaps a reason and way that Archer falls into love with Ellen.

In fact, the art of life is Archer's real life. Ellen begins to assume for Newland the whole of reality as against the sterile conformities of his "actual life":

Focused on the artistic writing, Wharton makes use of painting in order to delineate her character. Of course, Scorsese frames Wharton's characters in painterly effects. When Archer visited Ellen for the first time, Scorsese makes a change here, he relinquishes the erotic resonance of these paintings in favor of the long landscape panting that allow a "brushstroke" tracking shot from left to right gradually reveals, to Newland's eye and to ours, the long landscape painting that hangs in the Countess's drawing room. This technique can give a deeper impression on audience in movie, the camera sweeping across the long canvas that hangs in Ellen's house, it emphasizes by this means that film has the flexibility and the temporal dimension that painting lacks, which shows Archer's admiration for unconventional and rebelling Ellen, and admiration for the truth of life, at the same time, the brushstroke shows Ellen's unconventional taste. And the same technique is also used in the scene of Ellen's carriage leaving in the darkness; the color is heavy and imposed which can reflect the two people's mood, and the desperate situation of love between them.

\section{Ellen in Archer's Eye: Pygmalion's Sculpture}

And at the decisive moment in Wharton's novel - in Newport, after the honey moon that marks his marriage to May Welland - Newland is sent down to the water to fetch Ellen, who is standing near a "a sort of pagoda - like summerhouse" facing the bay, he mused, "she doesn't know she hasn't guessed. Shouldn't I know if she came up behind me, I wonder?" and contemplating Ellen as a spectator might view a sculpture; because "the lady in the summer-house seemed to be held by the same sight." he decides that "if she doesn't turn before that sail crosses the Lim Rock light I'll go back." [3] Obviously, here, Ellen becomes a sculpture, an inanimate figure, like Pygmalion's Galatea, coming magically to life. This is the extreme love and imagination for the art of life, this is also an evidence that Archer's hesitation and cowardice to the reality crudity. This is contrast: Ellen's courage for searching for happiness and freedom, like sun splintering up into a thousand fires is shining while Archer's dilemma of choosing between sense and sensibility.

Scorsese radically reduces this scene to the movement of a single sail boat very slowly from right to left across the cinematic frame. This is kind of "invasion of frame", a moment in which a moving object is represented slowly and deliberately entering an otherwise static cinematic frame, to call attention to the introduction of movement into a stasis of painting, thus creating the narrative of moving images that is film. At the moment, the figure of the woman is multiply encoded as a figure of art, as I have said above, for Archer, the sculpture of Ellen, if with enough preoccupation, will turn around into the life. But she after all doesn't turn around, so he turns and walked up the hill. He gives up his love.

So at the end of movie, the moment at which the golden light shining on Ellen's Paris window recalls Newland Archer's "decisive moment" at Newport to his memory. Wharton tells readers that for Newland "by some queer process of association that golden light became for him the pervading illumination in which she lived." [3] It is thirty years that gap between Archer's love and reality, eventually he found a place to appreciate the beauty and truth of life. There is no place for such true love, he understood, to some extent, he surrendered to the reality. What remain are that all his youthful dreams. However, in his heart, there is an age of innocence, not the innocent age of New 
York society, nor the hypocoristic innocence of those people including his wife. The period of his pursuing for the truth and love, is sculptured in Ellen's brave and rebelling body, which will finally come to life inside of him. So he needn't see her face to face, because this time, in Pygmalion-like fashion, Newland Archer succeeds in making his Galatea at this moment.[4]

\section{Symbols of Writing}

Due to the picturesque and colorful meaning in the movie, the symbols of writing are more vivid and highlighted. The yellow rose, the special symbol in the writing is more clear and important with its color impressed deeply in audience's vision. The audience should remember Archer's present for Ellen, a bunch of yellow roses. The yellow rose means wishes and cherish, rejected love, apology for love, fade love, goodbye, reserve a little care for other, no matter which one is the foreshow of the love story of Archer and Ellen. [5] When the two are appreciating the Opera in the theatre, Ellen says to herself, like asking Archer, "Will her love send her the yellow flower?" Newland gives Ellen love and care, making her not lonely in the cold and hypocritical society of New York, but Newland's hesitation and compromise with the rules and so-called morality, not to hurt May, forces her leave America but to the Europe. [6] As the flower's meaning, all is destined. Well, what Archer Newland sends may is lily of valley, lily stands for the virginity, the happiness and pride of virgin, also the happiness of return, because it is said the nightingale will fly back to the forest only when lily is blooming. Likewise, May has been aware of the passion of Archer for Ellen, and then uses her innocence or astuteness to detain her husband, maintains her composure to gain the chance of happiness in the hidden fight. Yellow rose is bright, and shining, full of passions and enthusiasm, but struggle to live under the sun, and lily is white and clean, with light, shallow but durable affection, which flavor can last for longer time. Women are often compared to the flower, the fate of the two women is reflected in the two kinds of flower, and Wharton uses the symbols of flower to reveal the subject: the women's role in the New York, which sends a poignant and exquisite feeling to the audience through Scorsese's camera.

And the costumes in the writhing is symbol with deep signification, the implication of the description of Old luxurious New Yorkers to every detail is to show the blankness under the beautiful and gorgeous clothes, like those extravagant balls, dinners and other ritualized social engagements. In this world, propriety is all, so when the appearance of Ellen's unconventional and bold costumes, Archer is attracted at once, but hated by the upper class because Ellen is much whispered about due to the free-thinking ideas she appears to have acquired in Europe. During the sweeping of camera, the specialty of Ellen's appearance and the embarrassing looks of the distinguished guests make a contrast. And the costume some time has another additional implication. When Ellen sends May an old and delicate lace as the marriage gift, which stands for the rituals of old New York, it indicates contradictive mood of Ellen, on one hand, she rebel against the old and hidebound traditions, on the other hand, she has a affinity for the place where she lived, which mirrors Wharton's dilemma.

The image and symbol in a novel is usually hidden between the lines, while, in the movie, it shows before the audience, making the subject more significant and clear. Scorsese's camera aims at the small and seeming trifle detail, so that Wharton's image and picture come to life.

\section{Narrative: Male or Female Stands}

We all know the Age of Innocence is the from Archer's view to observe the world. Archer's pursue for true and unconventional life and Archer's adherence to the moral commitment is the experience of Wharton's youth. In the movie, the use of a third-person, an old lady's voice-over is designed to give the impression of the narrator's voice - or actually of Wharton's voice, Scorsese tells us - and therefore to simulate the experience of reading the novel. Thus the voice of a woman is superimposed upon our experience of the film, constituting an aural dimension that both distances and draws the spectator in. however, in literature, it is Archer that leads us to the world of New York, giving much more space and time for readers to imagine and consider, and in the 
movie, a literal view suddenly has the voice beside the audience like a friend who has seen the film and couldn't help telling the secret and end of the story, and solve the problem we get stuck abruptly. [7] A viewpoint becomes indications, which more or less weaken the power of language.

Besides, the language of Wharton is sensitive and sentimental, and Scorsese is good at masculine and violent picturing. In this film, though we cannot see the strong and bloody scene of fights, we still feel the brutal suppression from the nature of human being, without blood but stifling. Wharton creates two women with opposite characteristics, in male Scorsese's view; he magnifies their virtues and merits and ignores some defects of women's role, especially for May, who is more sophisticated and cunning. It is a certain degree of sympathy. Because at the stand of Archer, completely male's view, Scorsese understands Archer's confusion and suffering, the affairs with the two women is imbedded in the growing up of hero, but, this is a coincidence with Wharton's creative origin, seeing women, reflecting the women from the male's viewpoint, implicit of illustrating her feminism, and Scorsese made it explicit.

\section{Conclusion:}

Undoubtedly, it is a successful example for Wharton conjoining the language and image in her the Age of Innocence. Due to his vivid description in painting that reflecting the theme of the novel - true love and art of life - with significant images and attractive sound, Scorsese film can reproduce the classic scene on the screen using the modern filmmaking skills.

I never thought Scorsese could make such a delicate and sensitive film, purely from a man's viewpoint, but the care for women's emotion. For Scorsese, film has triumphed over painting's entertainment of human figure by its capacity of rendering movement and thus for rendering life. This picture writing could reasonably serve as another metaphor for the simultaneously verbal and imagistic allusion in Wharton, as a metaphor for the multiple layer of visual and verbal allusion, it seems a particularly resonate choice.

Scorsese brings great energy to what could have been a very static story, although his style is more restrained and less elaborate than usual.

Art, for Wharton, is very important in her pursuit of true life in the conventional rules and morality. She expresses it with the sincerity and faith. Because she has experienced the unbearable but nostalgic carved in thinking of her, and what reveals before the readers are meaningful and fresh pictures. Her love for the art is the reason the younger representative of herself, Archer, falls in love with artistic image, Ellen which brings him into a real life rather than the actual life she is living. For Ellen, her later life in Europe is the mirror of Wharton herself, and she finally gives up her love, and escapes from the rituals and pyramid-ranking society for free life, which means she gives up something and gets something.

The combination of language and image is the charming point in Wharton, also seen Scorsese's edition.

\section{References}

[1] Gavin.Smith: Martin Scorsese Interviewed by Gavin Smith, Film Comment, 1993: 18

[2] Brigitte. Peu: The moment of Portraiture, movie and literature Beijing University Publishment 2004

[3] Edith Wharton,:The age of Innocence Beijing: Foreign Language Teaching and Research Press, 2004.8 P.17, 18,22 62, 194, 235, 321, 324

[4] R.W.B. Lewis Introduction of Age of Innocence New York: Scribner's 1968

[5] Y.F. Chen Comment on The age of Innocence, Overseas English Vol.2005 (3):34-35

[6] C.X Li: Analyzing the image, symbols and symbolisms in Age of Innocence Culture Research, Vol. 2006(12):156-156 
[7] X. Liu: tension of shadows and lines —male or female stands in Age of Innocence, Sichuan Drama, and Vol.2007 (2):64-65 